\title{
EVOLUTION OF MOBILE APPLICATIONS
}

\author{
Anachack Phongtraychack ${ }^{1,2 *}$, Darya Dolgaya ${ }^{1}$ \\ ${ }^{1}$ National Research Tomsk State University,634050, Tomsk, Russia \\ ${ }^{2}$ National University of Lao PDR. 7322, Dongdok, Vientiane, Lao PDR
}

\begin{abstract}
Currently, we can see the rapid evolution of mobile technology, which involves mobile communication, mobile hardware, and mobile software. Features of mobile phones largely depend on software. In contemporary information and communication age [1-4], mobile application is one of the most concerned and rapidly developing areas. At the same time, the development of mobile application undergoes great changes with the introduction of new software, service platforms and software development kits (SDK). These changes lead to appearance of many new service platforms such as Google with Android and Apple with iOS. This article presents the information about the evolution of mobile application, gives some statistical data on the past and present situation, demonstrates how individual users of mobile devices can benefit, and shows how mobile applications affect society from the ethical perspective.
\end{abstract}

\section{What is a mobile application?}

Mobile application is a software application designed to run on mobile devices such as smartphones and tablet computers. It is a result of recent technological innovations. Mobile applications have appeared because of the convergence of media, information technology, Internet and advanced technologies. In addition, for many years, mobile telecommunications have been under investigation by mobile device manufactures, mobile service providers, application developers, and many researchers in the sphere of information technology (IT) and information systems (IS). However, the most interesting area for research is mobile application evolution [5].

\subsection{Transactions on mobile applications}

Mobile devices and smartphones can be still considered as new ideas in the technology community. Compared to personal computers and laptops, the common mobile smartphones have only been around for a couple of years now. This leads to an interesting area of discussion on mobile payments online. In this increasingly digital world, it is not surprising that money will follow suit as well. Recent trends show that digital money kept in mobile wallets will soon replace physical cash and even credit cards. We can buy most products and

\footnotetext{
${ }^{*}$ Corresponding author: idea.phongtraychack@gmail.com
} 
services online these days via our laptops and mobile devices. It is easy to link this process to our bank accounts and online payment processors like PayPal.

SMS payments are currently one of the most popular methods of using mobile phones to pay for goods, services, or even to make person-to-person payments. In order to make SMS payments, a user needs only a phone with SMS capability. That is why many experts believe that because of the simple nature of SMS payments, they will continue to be a prospective area in mobile payments [6].

\subsection{Specific types of services by means of mobile application}

There are four specific types of services, which can be made of mobile application.

- Browser Access: The applications, which we use through native browser. For example, m.yahoo.com, www.google.com, m.redbus.in, etc.

- Hybrid Apps - Web: You need to install an application in your device; function of the particular application requires Internet. For example, Social Networking Apps (Facebook, Twitter), Instant Messenger (Skype), E-commerce (Flipkart), Internet Speed Testing (Speedtest), etc.

- Hybrid Apps - Mixed: You need to install the application in your device and function of the application may require Internet. For example, there are some games to play alone or to go online for playing with different players (multi player). This category also includes medical apps where you can keep a record of your health in order to share with your friends or doctor via internet.

- Native Apps: The applications, which are installed in the device. For example, Reminders, Few Games, etc [7].

\subsection{Types of software for building mobile application}

With a small investment, you can create and manage your mobile site or application using one of the platforms listed below:

- Appery.io.

- Mobile Roadie.

- TheAppbuilder.

- Good Barber.

- Appy Pie.

- AppMachine.

- GameSalad.

- BiznessApps.

- AppMakr.

- ShoutEm [8].

\section{The goals of mobile application}

The goal for developing mobile application is to provide conditions when maximum number of users use applications for maximum time. This means that the app developed should have the appropriate quality and purpose, so that maximum users across the globe like it. In this regard, applications should meet the following requirements:

- Conformance to the purposes of users.

- Capability to reach the majority of users. 
- Capability to be secure.

- Being user-friendly.

- Supporting continuous improvement and engagement [9].

\section{Mobile applications and mobile technology development}

\subsection{How do applications facilitate the development of the society?}

Mobile applications can facilitate the development of the society by contributing to resolution of the following problems:

- Quick search of job vacancy.

- Quick communication.

- Considerable cost saving.

- Saving time and increasing productivity.

- Less power consumption because of less computer use.

- Improvement of IT infrastructure in developing countries.

- Entertainment.

\subsection{Generations of mobile applications}

The handset manufacturers designed and developed mobile phones of the first-generation. The competition was fierce and trade secrets were guarded. They did not want to expose the secrets of their handsets, so they developed the phone software in-house. During this period, the first "time-waster" games started to appear. Nokia was famous for putting the video game Snake on some of its earliest phones (1970-ies). Because of such things, people started to change their attitude to communication. When prices for mobile phones have dropped and batteries were improved, more people began carrying handy devices.

\subsection{Why are mobile applications necessary?}

Currently, almost $80 \%$ of people are online through mobile devices. Most of these people prefer mobile applications because they are easy in use and perform tasks instantly.

Users become more dependable on mobile application when solving easy tasks like booking movie tickets, checking sport's scores, buying and selling, or many other similar routine activities. These tasks can be solved by a single click. A mobile app available on apps store has more chances to convert visits into business. That assists to increase rate of sales [10].

\section{Advantages, disadvantages and challenges of mobile application evolution}

\subsection{Advantages of mobile applications}

Mobile applications help users by connecting them to Internet services, which are more commonly accessed by means of notebook computers. People, especially young, are 
constantly using their mobile devices to browse the World Wide Web and if you are not there, you are missing the opportunities. There are three main advantages of mobile application:

- Apps are a constant reminder of your business.

Mobile apps reinforce your brand by increasing your visibility. An app gives a business more presence on a phone than a browser bookmark does because it is always visible on the screen of a phone. This helps building loyalty with customers because your business is around them all the time.

- Apps increase customer engagement.

Customers are calling out for mobile apps because they quickly connect them to businesses they most commonly want or need. Businesses are using apps to improve their processes and increase the level of accessibility by customers. The point of mobile apps is to smoothly connect and interact with customers, making it a valuable tool for the modern business.

- Apps reduce costs.

Apps reduce costs of SMS messages and paper newsletters. They simplify communications by securely, instantly and directly messaging customers. Apps reduce staff workload by information requests and phone calls [11].

\subsection{Disadvantages of mobile applications}

Mobile applications may also have some bad effect on the society. It includes the following aspects:

- When many Internet based mobile applications are available to teenagers, they are wasting time by using Facebook, Skype, YouTube etc. The young people are in risk when using Internet games or not appropriate applications.

- Most of people use mobile devices everywhere including buses, trains, offices, colleges, universities. It may disturb other people.

- Frequent use of mobile apps is bad for human health.

\subsection{The challenges of mobile applications}

One of the greatest challenges is to make your app visible so that people want to download it. If an app is not among the top 50-100 across a category in an app store, people will hardly ever download it.

One of the biggest challenges of mobile applications is their platform capability and limitation. In addition to interesting usability of mobile applications, they have some problems connected with platform and limitations. Let us consider a list of the main problems:

- Small screen size. On a mobile platform, it is difficult or impossible to view text and graphics like on a desktop computer screen.

- Lack of windows. We can see many windows at a time on a desktop. However, it can hardly be realized on a mobile platform.

- Navigation. Most mobile devices do not have mouse like pointer, so it has limited flexibility in navigation.

- Types of pages accessible. As a rule, mobile platforms do not support all types of file formats.

- Speed. The speed of processing and speed of connectivity of mobile platforms is slow. 
- Size of messages or email. Many devices support limited number of characters in message or email.

- Cost. The cost for cellphones, mobile applications and Internet connection is high [12].

\section{An overview of the famous mobile applications (2017)}

According to comScore's annual U.S. mobile apps report, Americans spend more than half $(57 \%)$ of their digital media consumption time in apps, which is about the same as a year ago. It means that the dramatic shift to mobile apps has now leveled out in the U.S. Table 1 shows the apps-leaders, according to comScore, as measured by their penetration of the U.S. mobile app audience [13].

Table 1. Top 10 Mobile Apps by Penetration of App Audience in the USA, June 2017

\begin{tabular}{|c|c|c|}
\hline Rank & Applications & Percentage \\
\hline 1 & Facebook & $81 \%$ \\
\hline 2 & Youtube & $71 \%$ \\
\hline 3 & Messenger & $68 \%$ \\
\hline 4 & Google Search & $61 \%$ \\
\hline 5 & Google Maps & $57 \%$ \\
\hline 6 & Instragram & $50 \%$ \\
\hline 7 & Snapchat & $50 \%$ \\
\hline 8 & Google Play & $47 \%$ \\
\hline 9 & Gmail & $44 \%$ \\
\hline 10 & Pandora & $41 \%$ \\
\hline
\end{tabular}

\subsection{Case study of mobile applications of China}

China is the biggest mobile phone market in the world. The number of mobile phone users is more than 850 million. Among them, 277 million people use mobile net citizens, which is becoming the main driving force for the rise of general net citizen scale in China.

Teenagers contribute a considerable part to mobile communication market. A large proportion of teenagers in Korea (80.6\%) and Japan (77.3\%) own mobile phones. In China, $48.9 \%$ of teenagers aged between 12 and 18 are mobile users. There is a big market potential to attract the other half of teenagers. Chinese mobile booming market and the success of applications on smartphones are well-known facts. It is a huge booming market where all the companies are trying to be the best. However, it is not such an easy task, since there are many things to know about this market.

\subsubsection{Understanding of Chinese mobile market}

There is a huge potential of Chinese customers with 850 million users of smartphones. Let us go through several points here to understand the overall Chinese mobile market.

First, OS vs iOS and Android are widely dominating the market owning most of the market share; however, even if the non-friendly relation with the big Apple, iOS is the second one owning the market share. We will go deeper on this point in further analysis. 
Second, Chinese people are not willing to pay for mobile applications. They consider the new wave of technology as a way to make their everyday life easier. However, most of applications revenue in China are made inside the application, which includes all the purchases inside the app, for example, additional features for a game, additional functions for dating app, etc.

Third, Chinese people are selective about the choice and the selection of their applications. They need to have a wide range of options among applications. Most of downloaded applications are still mobile games.

Fourth, you have to choose your mobile application partner. There are more than 500 application stores, you might feel lost among this numerous number of applications stores, they all have different functions, some focus on games, while others tend to be more social [14].

\section{Conclusion}

Mobile phones have changed our world completely. People use them for leisure time, business, and education. Mobile phones are not just mobile phones anymore. People rely on them for video chatting, voice calls, surfing internet, taking pictures, playing games, etc. Mobile phones have become a part of everyday life and we cannot imagine our life without a mobile phone. In addition, much of the capabilities of smartphones revolve around the applications they offer. This is very important in determining the future of smartphones. Applications give smartphones an extra edge that ordinary phones do not have. Such apps include advanced photo sharing, gaming or internet service. The opportunities for the future of mobile application are endless. It will only take some time to see, which of these innovations will be a part of our everyday life.

\section{Acknowledgements}

The research presented in this paper was supported by the Russian Foundation for Basic Research (grant No 16-29-04388/17). The authors are grateful to Tatiana B. Rumyantseva from Tomsk State University for her assistance in preparing the article.

\section{References}

[1] V. Syryamkin, V. Shidlovsky. Correlation-extremal direction-finding systems (Tomsk State University publishing house, 2010)

[2] S.V. Shidlovskii, J. Comp. Sys. Sci. Int 45, 282 (2006)

[3] D.V. Shashev, MATEC Web Conf. 79, (2016)

[4] D.V. Shashev, S.V. Shidlovskiy, J. Phy: Conf. Ser. 881, (2017)

[5] Mobile app. [Electronic resource] URL: https://en.wikipedia.org/wiki/Mobile_app

[6] J. Rocheleau. 6 Safety Steps To Making Secure Mobile Transactions. URL: http://www.hongkiat.com/blog/secure-mobile-payment-tips/

[7] Types of mobile application. URL: http://softwaretestinggarbage.blogspot.ru/2012/10/types-of-mobile-application.html

[8] Gr. Smith. 10 Excellent Platforms for Building Mobile Apps. URL: http:// http://mashable.com/2013/12/03/build-mobile-apps/\#XycLK6j7ZkqA

[9] Yo. De. What is the goal of the mobile app development? URL: https://www.quora.com/What-is-the-goal-of-the-mobile-app-development 
[10] Ch. Siegl. Is it necessary to have a mobile app when you already have a website? URL: https://www.quora.com/Is-it-necessary-to-have-a-mobile-app-when-you-already-havea-website

[11] Benefits of mobile apps. URL: http://vividus.com.au/insights/benefits-of-mobile-apps/

[12] J. Shore. Challenges of developing applications for mobile platforms. URL: http://searchcloudapplications.techtarget.com/podcast/Challenges-of-developingapplications-for-mobile-platforms

[13] Top 10 most popular apps of $2017 . \quad$ URL: https://www.recode.net/2017/8/24/16197218/top-10-mobile-apps-2017-comscore-chartfacebook-google

[14] Solutions to Market your mobile application in China. URL: http://marketingtochina.com/solutions-to-market-your-mobile-application-in-china/ 